\title{
Theory and usage of tensiomyography and the analysis method for the patient with low back pain
}

\author{
Sihwa Park ${ }^{1,2 *}$ \\ 'Department of Sports and Leisure Studies, Korea University, Sejong, Korea \\ ${ }^{2}$ Research Institute of Sports and Industry Science, Hanseo University, Seosan, Korea
}

Tensiomyography (TMG) is an injury detecting tool for muscle group imbalances and/or side-to-side asymmetries. It is liable to detect to measure contractile properties and mechanical responses based on muscle belly displacement. Although other previous papers have well suggested the methods for examining the several muscle groups using TMG, a detecting method for the imbalances in low back muscles has not been investigated, and no review papers have been compiled. Therefore, this study aimed to synthesize the theories of the previous studies observed using TMG and to briefly summarize its usefulness by performing simple experiments on the left and right regions of the erector spinae muscles, which may be a problem using TMG for patients with low back pain.

Keywords: Tensiomyography, Muscle belly, Erector spinae, Low back pain

\section{INTRODUCTION}

The number of people suffering from low back pain (LBP), including spinal disorders and herniated intervertebral discs, has increased every year. Several researchers reported that LBP is related to bad posture and deformation of the spinal alignment, excluding those with native vertebral disorders. Spinal malalignment is a deformity of normal spinal alignment, including lordosis, kyphosis, scoliosis, forward head posture, and pelvic torsion (Kingma and van Dieën, 2009; Meakin et al., 2008). The alignment of the pelvis and lumbar vertebrae affects other parts of the body, and it is likely to cause further health problems or complications. Alterations in the curvatures of the lumbar and/or thoracic vertebrae affect postural changes of the neck and head. The vertebrae comprise an articular chain, where changes in one part of the column create biomechanical interactions that affect the alignment by creating compensations in adjacent vertebrae (LeVeau and Bernhardt, 1984). Control of posture and balance of the body is a process of complex interactions of various tissues in the body and forces gen-

erated from outside. The spinal column is an essential element to maintain normal balance (Shumway-Cook and Woollacott, 2000). Maintaining correct posture is important because it affects the functional efficiency of the musculoskeletal system and the body as a whole. When the curvature of the vertebra occurs, the cervical, thoracic, lumbar, and sacral joints develop organically in the upright posture by imposing elasticity against compression pressure. That is, when a joint's function deteriorates, it compensates to maintain balance in the sagittal plane at other sites. If this condition persists, changes in the musculoskeletal pattern cause pain or other clinical problems (Nault et al., 2002).

In spinal diseases, pain is a major symptom and an important target for treatment. In terms of treatment outcomes, pain is an important measure for determining effectiveness. Correctly measuring pain in patients with LBP is important for evaluating the outcomes of the treatment of LBP and for comparing the results between treatment methods. Because LBP is subjective, it is impossible to accurately measure pain levels because of conditions such as physical, psychological, emotional, or environmental states.

*Corresponding author: Sihwa Park (D) https://orcid.org/0000-0001-6256-9970 Department of Sports and Leisure Studies, Korea University, 2511 Sejong-ro, Sejong 30019, Korea

E-mail address: slim@korea.ac.kr

Received: June 1, 2020 / Accepted: July 4, 2020
This is an Open Access article distributed under the terms of the Creative Commons Attribution Non-Commercial License (https://creativecommons.org/licenses/by-nc/4.0/) which permits unrestricted non-commercial use, distribution, and reproduction in any medium, provided the original work is properly cited. 
Despite the fact that we have developed many methods to quantify pain, reliability is debatable, and there is no way to fully measure the characteristics of the paraspinal muscles in the context of LBP.

The erector spinae are the most important paraspinal muscles for supporting the spine. They are a group of muscles and tendons that run more or less the length of the spine bilaterally from the sacral region and hips to the base of the skull. The muscle fibers are oriented differently in various segments of the muscle chain. Bogduk et al. (1992) reported that the fibers of the lumbar erector spinae are oriented more obliquely to the long axis in the back than in the thoracic portions. The lumbar part of the erector spinae muscles exerts shear forces on the upper lumbar levels (Bogduk, 1980), and this mechanical adaptation might enhance muscle endurance; the muscles fatigue differently depending on the segment in question.

A static functional test of the erector spinae of patients with LBP is recommended when a dynamic functional test is not possible because of moderate-to-severe LBP. Many noninvasive diagnostic methods have been developed based on imaging and electromagnetics. Ultrasound, magnetic resonance imaging, and electromyography are commonly used. Surface electromyography, sonomyography, mechanomyography, myotonometry, and tensiomyography (TMG) are all used to evaluate muscle function (Ballyns et al., 2011). Because TMG can transmit data through mechanical signals, it is less sensitive to external noise, is not affected by skin resistance or sweating, and does not require much proficiency. TMG is used as a static function test; however, it is rarely used in patients with LBP. The categories of normal or abnormal waves are not been defined. Because TMG is noninvasive, easy to apply to specific muscles, and involves a simple indicator, it can be used to understand changes in muscle function. Because there is little known measurement method for LBP using by TMG, this present study aimed to inform what the usefulness of TMG is and if TMG is useful in clinical diagnosis by detecting the characteristics of the erector spinae of LBP patients.

\section{TENSIOMYOGRAPHY AND MUSCLE CONTRACTILE PROPERTIES}

TMG measures contractile properties of muscles (Dahmane et al., 2001). It assesses mechanical responses based on radial muscle belly displacement induced by a single electrical stimulus (TousFajardo et al., 2010). It is performed using a TMG device (TMG, TMG100, TMG-BMC Ltd., Ljubljana, Slovenia). This instrument includes an electrical stimulator and a data acquisition subunit, a sensor (probe), electrodes, electrical stimulator, and a tripod with a manipulating hand that works with a software interface installed on a laptop (Fig. 1) (Dahmane et al., 2001).

TMG has been used in exercise rehabilitation, sports medicine, and clinical research. Its data can be used to determine muscle fiber type (e.g., by comparing displacement signal and muscle histochemistry/amounts of myosin heavy chain) and muscle status/condition (fatigue, potentiation, inhibition, and stress). It can also be used to diagnose functional muscular symmetry, either temporal or morphological, to evaluate muscular synchronization and for fast de-

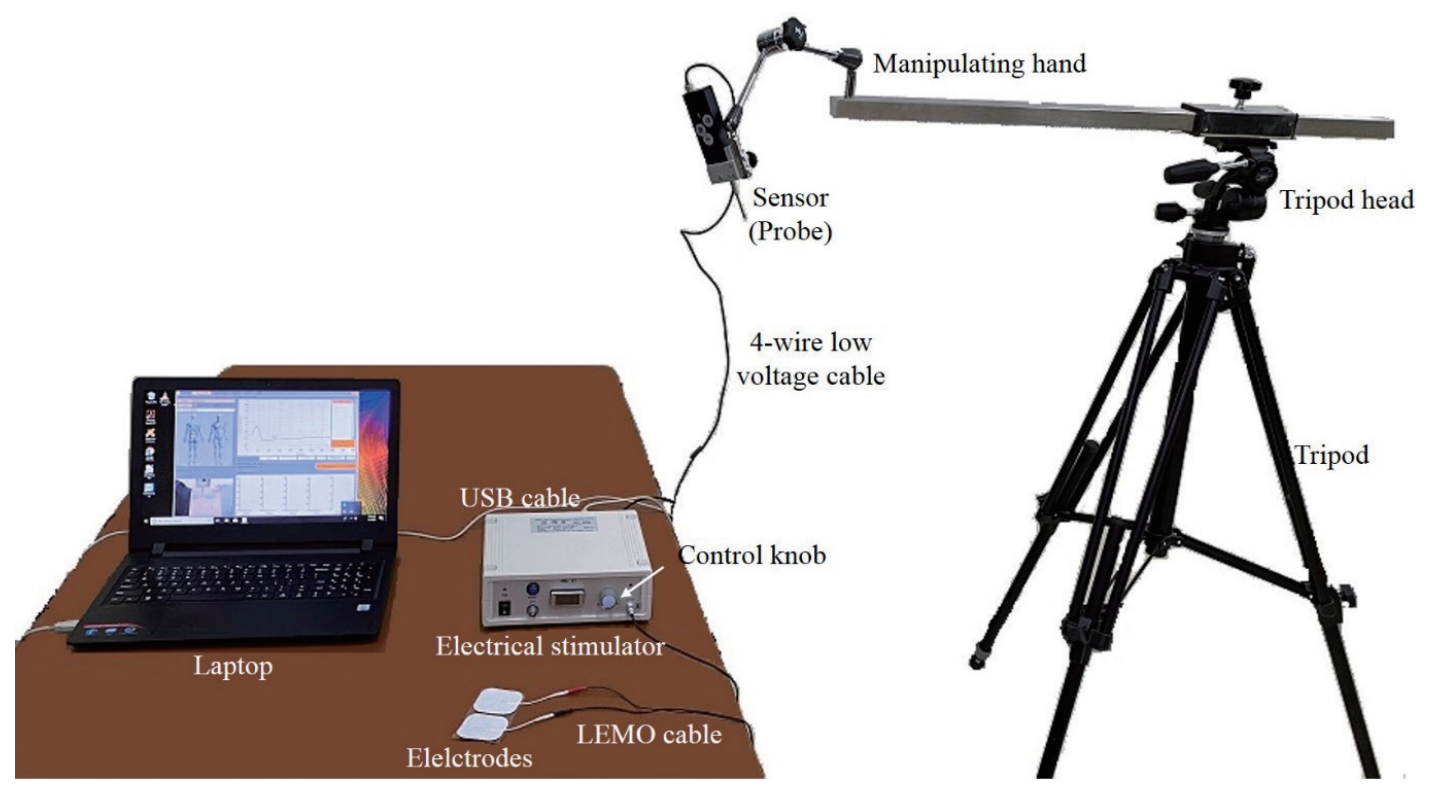

Fig. 1. Tensiomyography measurement instrument. 
tection (less than $5 \mathrm{~min}$ ) of infra-clinical lesions in muscles (Dahmane et al., 2005; García-Manso et al., 2011; Rusu et al., 2013).

\section{MEASUREMENT STEPS AND RECORDING OF TENSIOMYOGRAPHY}

A special sensor is placed on the muscle to be measured. The sensor contains a tip designed to register muscle contraction. Muscle contraction is induced with twitch type $(1 \mathrm{msec})$ of surface electrical stimulus. Contraction of muscle under isometric conditions results in muscle belly displacement. A TMG sensor is connected to a computer running software that records displacement of the sensor tip during the test and displays results in real time.

TMG-specific software receives signals on the $1-\mathrm{kHz}$ scale. Two supra-maximal responses are stored and the average is calculated. The supra-maximal stimulation corresponds to minimal stimulation and it determines maximum amplitude of muscular deformation, recorded as maximal displacement (Rusu et al., 2013). The output of TMG is a displacement-time signal evaluated with standard parameters (Dahmane et al., 2001). As shown in Fig. 2, these parameters are delay time $(\mathrm{Td})$, contraction time $(\mathrm{Tc})$, sustain time (Ts), relaxation time (Tr), and maximal displacement

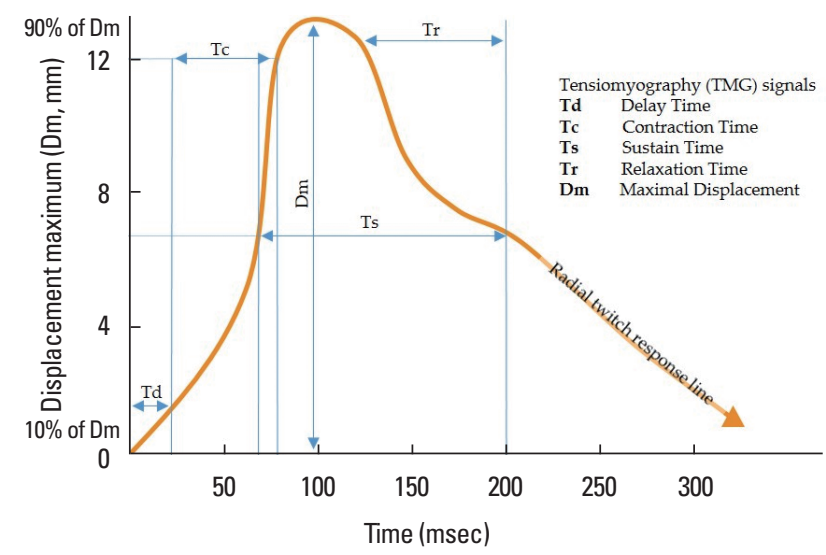

Fig. 2. Tensiomyographic signals in a period of radial twitch response.
(Dm). Td refers to the time between the electrical impulse and $10 \%$ of the contraction. Tc is the time between $10 \%$ and $90 \%$ of the contraction. Ts and $\operatorname{Tr}$ are the times between $50 \%$ of the contraction and $50 \%$ of the relaxation and the time between $90 \%$ and $50 \%$ of the relaxation, respectively. Dm is an important signal, representing the period of radial twitch response; it corresponds to maximal displacement of a muscle contraction, although recent studies have referred to changes in $\mathrm{Dm}$ as changes in contraction velocity (Macgregor et al., 2016). The radial twitch response (Vrn) is shown in Fig. 2. The equation describing this parameter is as follows (Krizaj et al., 2008):

$$
\mathrm{V}_{r}=\frac{\Delta d_{r}}{\Delta t_{c}}[\mathrm{~mm} / \mathrm{s}]\left|\mathrm{V}_{m}=\frac{\mathrm{V}_{r}}{\mathrm{D} m}=\frac{\Delta d_{r} / \Delta t_{c}}{\mathrm{D} m}\left[\frac{\mathrm{mm} / \mathrm{s}}{\mathrm{mm}}\right]\right| \mathrm{V}_{m}=\frac{0.8}{\mathrm{t}_{c}}[\mathrm{~mm} / \mathrm{s}]
$$

where $\operatorname{Vrn}$ is the normalized speed response (0.8/Tc), $\Delta \mathrm{dr}$ is the maximal amplitude of the muscle response, and $\Delta \mathrm{Tc}$ represents the increase in muscle contraction time between $10 \%$ and $90 \%$ of the muscle response. $\mathrm{Vr}$ is the speed response without normalization and the 0.8 is a constant. The reproducibility and the validity of this method have been assessed by several authors. The reliability and degree of error of the parameter included in the Vrn equation (Tc) were also tested previously (Atkinson and Nevill, 1998; Ditroilo et al., 2013; Krizaj et al., 2008; Tous-Fajardo et al., 2010).

Lateral symmetry (LS) can be tested, which comprises the comparisons of the same muscle on both limbs of the body (e.g., dominant limb vs. nondominant limb). LS of the erector spinae can be recorded from left and right sides. The equation generated by TMG to calculate lateral symmetries is as follows:

$$
\mathrm{LS}=100 \cdot\left(0.1 \cdot \frac{\min \left(T d_{R} T d_{L}\right)}{\max \left(T d_{R} T d_{L}\right)}+0.6 \cdot \frac{\min \left(T c_{R} T c_{L}\right)}{\max \left(T C_{R} T C_{L}\right)}+0.1 \cdot \frac{\min \left(T s_{R} T s_{L}\right)}{\max \left(T s_{R} T s_{L}\right)}+0.2 \cdot \frac{\min \left(D m_{R} D m_{L}\right)}{\max \left(D m_{R} D m_{L}\right)}\right)
$$

where $\mathrm{LS}$ is lateral symmetry; $\mathrm{TdR}$ and $\mathrm{TdL}$ are values of right and left sides, respectively; TCR and TCL are values of right and left sides, respectively; TsR and TsL are value of right and left sides, respectively; and $\mathrm{DmR}$ and $\mathrm{DmL}$ are values of right and left sides, respectively. As suggested above, this study summarized as Table 1.

Table 1. Analysis and function of tensiomyographic parameters

\begin{tabular}{lll}
\hline Parameters & Time from $0 \%$ to $10 \%$ of Dm & Analysis \\
\hline Delay time $(\mathrm{Td})$ & Time from $10 \%$ to $90 \%$ of $\mathrm{Dm}$ & Correlation ratio of slow muscle fiber (type I) and Tc \\
Contraction time $(\mathrm{Tc})$ & Distance time between graph in the $50 \%$ section of Dm & Efficient measurement of muscle fatigue rate \\
Sustain time $(\mathrm{Ts})$ & Time from $90 \%$ to $50 \%$ of Dm during muscle relaxation & Increase as the muscular dystrophy increases \\
Relaxation time $(\mathrm{Tr})$ & Vertical distance $(\mathrm{mm})$ that the curve reaches to the peak due to the & Decrease as the tension or stiffness increase \\
Maximal displacement $(\mathrm{Dm})$ & displacement of muscle formed by muscle contraction &
\end{tabular}




\section{TENSIOMYOGRAPHY IN THE PATIENTS WITH LOW BACK PAIN}

TMG is a simple, selective, and noninvasive method for measuring skeletal muscle contractile parameters using a linear displacement sensor. It assesses skeletal muscle thickening and lowfrequency lateral oscillations of active skeletal muscle fibers during twitch contractions (Pisot et al., 2008). It was originally designed to be used by medical professionals, but it has transitioned from medicine to sports medicine, and it is now being utilized in exercise rehabilitation programs and for postinjury rehabilitation quantification (Raeder et al., 2016). Because of its noninvasive nature, TMG provides rapid accurate diagnostic data without discomfort or disruption of personal routines (Fig. 3). In practice, TMG and isokinetic muscle testing are useful as diagnostic methods for comparing left and right extremities and for analyzing muscle contraction properties of agonists and antagonists. Despite

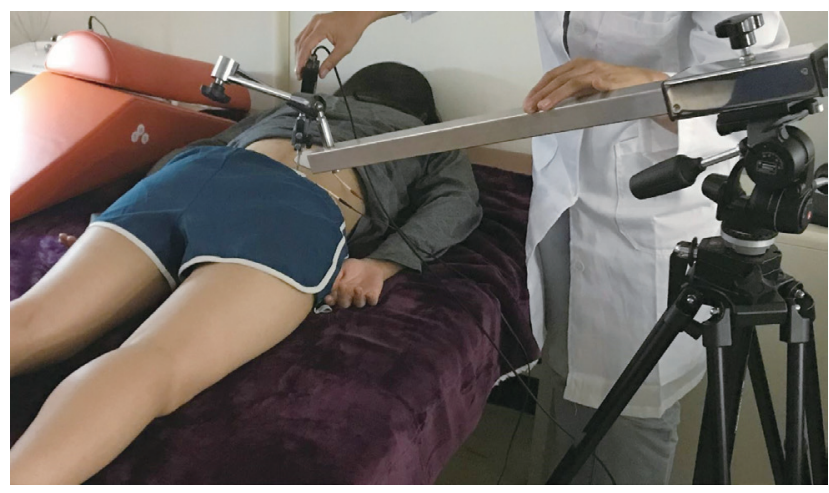

Fig. 3. Tensiomyography measurement scene for the low back pain patient This figure was published with the consent of the parties. the fact that isokinetic muscle testing is not used in patients with LBP, the TMG can be performed noninvasively while the patient is stable; therefore, there is little difficulty in measuring left and right erector spinae muscles and/or rectus abdominis in patients with LBP.

The Tc of a muscle was found to be longer in type I muscle fibers, and shorter in type II fibers (Valencic and Knez, 1997). Dahmane et al. (2001) reported a very high correlation between the ratio of Tc and type I muscle fibers. It is said that Dm increases with increasing muscle atrophy, whereas Dm is smaller under muscle tension and stiffness (Pisot et al., 2008). Hunter et al. (2012) asserted that Dm can detect exercise-induced muscle damage as well as recovery. It was possible to measure LS and functional symmetry in that study. In other words, the risk of injuries may increase with the rise in stiffness because of decreased Dm, suggesting the possibility of promoting exercise performance using TMG monitoring (Wilson et al., 2019). TMG was used as an evaluation tool for muscle function by comparing the injured side with the healthy side of a specific ligament in athletes (AlentornGeli et al., 2015a; Alentorn-Geli et al., 2015b; Alvarez-Diaz et al., 2016a; Alvarez-Diaz et al., 2016b). There were significantly increased $\mathrm{Ts}$, $\mathrm{Tr}$, and $\mathrm{Td}$ of left erector spinae and in $\mathrm{Tc}$ and $\mathrm{Td}$ of right erector spinae only in the exercise intervention group after 8 weeks. Specifically, although the Ts of left erector spinae and the Td of left and right erector spinae between the exercise intervention group and the control group were not significantly different at baseline, these values were significantly different after 8 weeks. In other words, if the erector spinae muscles were weakened by LBP, TMG could detect imbalances between normal and/or abnormal sides of these muscles (Fig. 4).
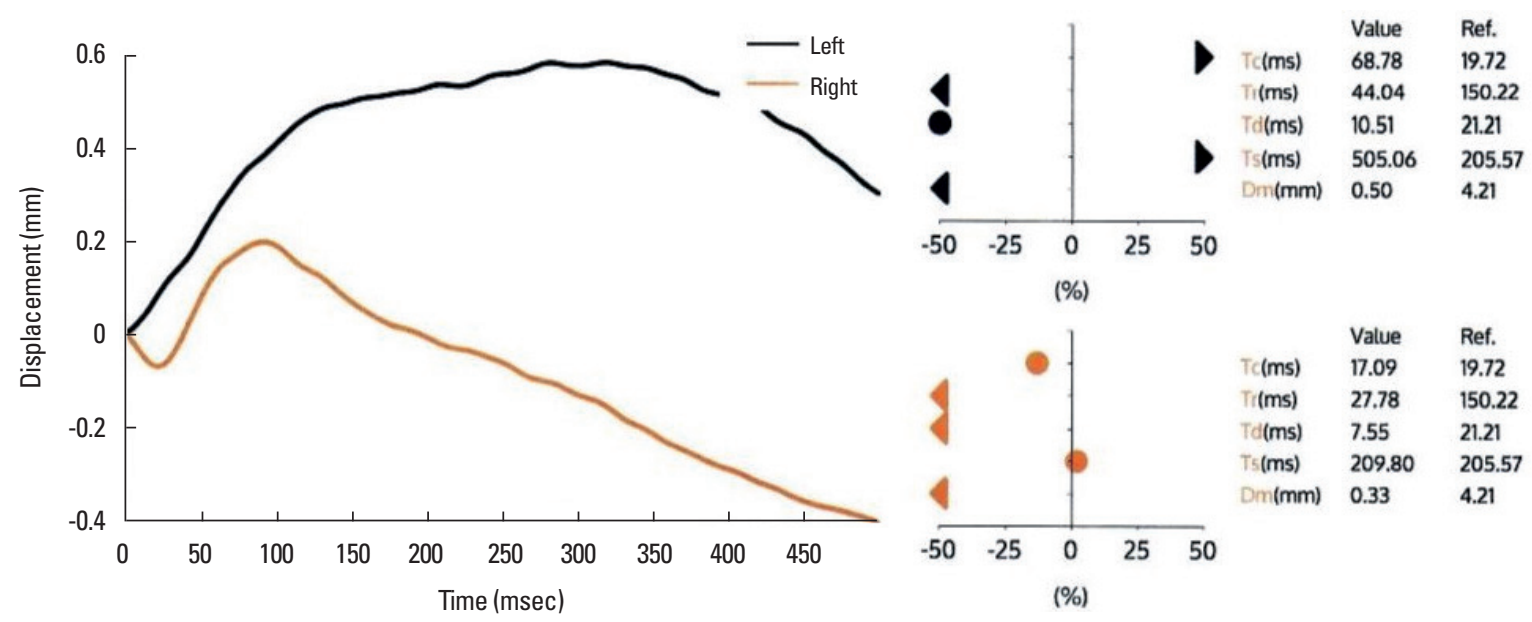

Fig. 4. Imbalance between normal and abnormal sides of erector spinae muscles. 
Fig. 4 shows that the Tc of the left erector spinae was $68.78 \mathrm{msec}$, whereas that of the right erector spinae was $17.09 \mathrm{msec}$. Even when compared with reference value (left Tc 19.72 msec; right Tc 19.72 $\mathrm{msec})$, it could be seen that there was a significant difference, and the shape of the graph appeared to show a significant difference. There also were significant differences in $\mathrm{Tr}$, $\mathrm{Td}, \mathrm{Ts}$, and $\mathrm{Dm}$ between the left and right erector spinae muscles.

\section{LOW BACK PAIN ASSESSED USING TENSIOMYOGRAPHY}

Myofascial trigger points related to LBP may be active or latent when considering recognition of pain in the spine (Ge and ArendtNielsen, 2011; Gerber et al., 2013; Lluch et al., 2015). Active and/ or latent myofascial trigger points generate spontaneous perceptible pain and may produce local or referred pain after stimulation (Ge and Arendt-Nielsen, 2011). The latter is as prevalent in patients with various spinal conditions as is the case in healthy subjects (Chiarotto et al., 2016). Nevertheless, both myofascial trigger points show differences in terms of electrophysiological activity levels (Yu and Kim, 2015), biochemical milieu (Shah et al., 2008), sonographic characteristics (Takla et al., 2016), thermography (Dibai-Filho and Guirro, 2015), magnetic resonance elastography (Chen et al., 2007), and TMG results (Calvo-Lobo et al., 2017). Calvo-Lobo et al. (2017) compared TMG, sonoelastography, and pressure pain threshold differences between the palpation areas of active and latent myofascial trigger points with respect to control points in the lumbar erector spinae muscles in subjects with LBP. A cross-sectional study was performed as follows: a convenience sample of 60 points (20 active myofascial trigger points, 20 latent myofascial trigger points, and 20 control points) was registered bilaterally in the lumbar erector spinae muscles from subjects with nonspecific lumbopelvic pain. With respect to the active myofascial trigger point, a moderate positive correlation was observed between the pressure pain threshold and Dm. Considering the control trigger points, a moderate positive correlation was shown between sonoelastography and $\mathrm{Td}$ at normal sites.

\section{CONCLUSIONS}

Several studies have used TMG as an injury prevention tool for the detection of muscle group imbalances and side-to-side asymmetries (García-García et al., 2019; Sánchez-Sánchez et al., 2018). It is also used to measure contractile properties (Dahmane et al., 2001; Đorđević et al., 2011) and mechanical responses based on radial muscle belly displacement (Tous-Fajardo et al., 2010). This short review suggests that it is necessary to use TMG in perform clinical trials to identify characteristics that appear in various erector spinae areas in LBP patients, and to quantify normal values. In other words, the first tasks are to identify the characteristics of various abnormal erector spinae muscles using TMG and to identify treatment methods. Future directions should be multidimensional for patients with LBP: validation with muscle force and/or endurance; determining trends of physiological adaptation through longitudinal designs; characterizing muscle fatigue; and developing the application of TMG for measurement of dynamic muscle contractions. In addition, it is hopeful that many studies will be conducted on LBP patients based on this study.

\section{CONFLICT OF INTEREST}

No potential conflict of interest relevant to this article was reported.

\section{REFERENCES}

Alentorn-Geli E, Alvarez-Diaz P, Ramon S, Marin M, Steinbacher G, Boffa JJ, Cuscó X, Ballester J, Cugat R. Assessment of neuromuscular risk factors for anterior cruciate ligament injury through tensiomyography in male soccer players. Knee Surg Sports Traumatol Arthrosc 2015a; 23:2508-2513.

Alentorn-Geli E, Alvarez-Diaz P, Ramon S, Marin M, Steinbacher G, Rius $\mathrm{M}$, Seijas R, Ares O, Cugat R. Assessment of gastrocnemius tensiomyographic neuromuscular characteristics as risk factors for anterior cruciate ligament injury in male soccer players. Knee Surg Sports Traumatol Arthrosc 2015b;23:2502-2507.

Alvarez-Diaz P, Alentorn-Geli E, Ramon S, Marin M, Steinbacher G, Boffa

JJ, Cuscó X, Ares O, Ballester J, Cugat R. Effects of anterior cruciate ligament injury on neuromuscular tensiomyographic characteristics of the lower extremity in competitive male soccer players. Knee Surg Sports Traumatol Arthrosc 2016a;24:2264-2270.

Alvarez-Diaz P, Alentorn-Geli E, Ramon S, Marin M, Steinbacher G, Rius M, Seijas R, Ballester J, Cugat R. Comparison of tensiomyographic neuromuscular characteristics between muscles of the dominant and non-dominant lower extremity in male soccer players. Knee Surg Sports Traumatol Arthrosc 2016b;24:2259-2263.

Atkinson G, Nevill AM. Statistical methods for assessing measurement error (reliability) in variables relevant to sports medicine. Sports Med 1998;26:217-238.

Ballyns JJ, Shah JP, Hammond J, Gebreab T, Gerber LH, Sikdar S. Objec- 
tive sonographic measures for characterizing myofascial trigger points associated with cervical pain. J Ultrasound Med 2011;30:1331-1340.

Bogduk N. A reappraisal of the anatomy of the human lumbar erector spinae. J Anat 1980;131(Pt 3):525-540.

Bogduk N, Macintosh JE, Pearcy MJ. A universal model of the lumbar back muscles in the upright position. Spine (Phila Pa 1976) 1992;17: 897-913.

Calvo-Lobo C, Diez-Vega I, Martínez-Pascual B, Fernández-Martínez S, de la Cueva-Reguera M, Garrosa-Martín G, Rodríguez-Sanz D. Tensiomyography, sonoelastography, and mechanosensitivity differences between active, latent, and control low back myofascial trigger points: A cross-sectional study. Medicine (Baltimore) 2017;96:e6287.

Chen Q, Bensamoun S, Basford JR, Thompson JM, An KN. Identification and quantification of myofascial taut bands with magnetic resonance elastography. Arch Phys Med Rehabil 2007;88:1658-1661.

Chiarotto A, Clijsen R, Fernandez-de-Las-Penas C, Barbero M. Prevalence of myofascial trigger points in spinal disorders: a systematic review and meta-analysis. Arch Phys Med Rehabil 2016;97:316-337.

Dahmane R, Djordjevic S, Simunic B, Valencic V. Spatial fiber type distribution in normal human muscle Histochemical and tensiomyographical evaluation. J Biomech 2005;38:2451-2459.

Dahmane R, Valen i V, Knez N, Er en I. Evaluation of the ability to make non-invasive estimation of muscle contractile properties on the basis of the muscle belly response. Med Biol Eng Comput 2001;39:51-55.

Dibai-Filho AV, Guirro RRJ. Evaluation of myofascial trigger points using infrared thermography: a critical review of the literature. J Manipulative Physiol Ther 2015;38:86-92.

Ditroilo M, Smith IJ, Fairweather MM, Hunter AM. Long-term stability of tensiomyography measured under different muscle conditions. J Electromyogr Kinesiol 2013;23:558-563.

Đorđević S, Stančin S, Meglič A, Milutinović V, Tomažič S. MC sensor-a novel method for measurement of muscle tension. Sensors (Basel) 2011;11:9411-9425.

García-García O, Cuba-Dorado A, Álvarez-Yates T, Carballo-López J, Iglesias-Caamaño M. Clinical utility of tensiomyography for muscle function analysis in athletes. Open Access J Sports Med 2019;10:49-69.

García-Manso JM, Rodríguez-Ruiz D, Rodríguez-Matoso D, de Saa Y, Sarmiento S, Quiroga M. Assessment of muscle fatigue after an ultraendurance triathlon using tensiomyography (TMG). J Sports Sci 2011;29:619-625.

Ge HY, Arendt-Nielsen L. Latent myofascial trigger points. Curr Pain Headache Rep 2011;15:386-392.

Gerber LH, Sikdar S, Armstrong K, Diao G, Heimur J, Kopecky J, Turo D, Otto P, Gebreab T, Shah J. A systematic comparison between subjects with no pain and pain associated with active myofascial trigger points.

\section{PM R 2013;5:931-938.}

Hunter AM, Galloway SD, Smith IJ, Tallent J, Ditroilo M, Fairweather MM, Howatson G. Assessment of eccentric exercise-induced muscle damage of the elbow flexors by tensiomyography. J Electromyogr Kinesiol 2012;22:334-341.

Kingma I, van Dieën JH. Static and dynamic postural loadings during computer work in females: sitting on an office chair versus sitting on an exercise ball. Appl Ergon 2009;40:199-205.

Krizaj D, Simunic B, Zagar T. Short-term repeatability of parameters extracted from radial displacement of muscle belly. J Electromyogr Kinesiol 2008;18:645-651.

LeVeau BF, Bernhardt DB. Developmental biomechanics. Effect of forces on the growth, development, and maintenance of the human body. Phys Ther 1984;64:1874-1882.

Lluch E, Nijs J, De Kooning M, Van Dyck D, Vanderstraeten R, Struyf F, Roussel NA. Prevalence, incidence, localization, and pathophysiology of myofascial trigger points in patients with spinal pain: a systematic literature review. J Manipulative Physiol Ther 2015;38:587-600.

Macgregor LJ, Ditroilo M, Smith IJ, Fairweather MM, Hunter AM. Reduced radial displacement of the gastrocnemius medialis muscle after electrically elicited fatigue. J Sport Rehabil 2016;25:241-247.

Meakin JR, Smith FW, Gilbert FJ, Aspden RM. The effect of axial load on the sagittal plane curvature of the upright human spine in vivo. J Biomech 2008;41:2850-2854.

Nault ML, Allard P, Hinse S, Le Blanc R, Caron O, Labelle H, Sadeghi H. Relations between standing stability and body posture parameters in adolescent idiopathic scoliosis. Spine (Phila Pa 1976) 2002;27:1911-1917.

Pisot R, Narici MV, Simunic B, De Boer M, Seynnes O, Jurdana M, Biolo G, Mekjavić IB. Whole muscle contractile parameters and thickness loss during 35-day bed rest. Eur J Appl Physiol 2008;104:409-414.

Raeder C, Wiewelhove T, Simola RÁ, Kellmann M, Meyer T, Pfeiffer M, Ferrauti A. Assessment of fatigue and recovery in male and female athletes after 6 days of intensified strength training. J Strength Cond Res 2016;30:3412-3427.

Rusu LD, Cosma GG, Cernaianu SM, Marin MN, Rusu PF, Ciocănescu DP, Neferu FN. Tensiomyography method used for neuromuscular assessment of muscle training. J Neuroeng Rehabil 2013;10:67.

Sánchez-Sánchez J, Bishop D, García-Unanue J, Ubago-Guisado E, Hernando E, López-Fernández J, Colino E, Gallardo L. Effect of a Repeated Sprint Ability test on the muscle contractile properties in elite futsal players. Sci Rep 2018;8:17284.

Shah JP, Danoff JV, Desai MJ, Parikh S, Nakamura LY, Phillips TM, Gerber LH. Biochemicals associated with pain and inflammation are elevated in sites near to and remote from active myofascial trigger points. Arch Phys Med Rehabil 2008;89:16-23. 
Shumway-Cook A, Woollacott M. Attentional demands and postural control: the effect of sensory context. J Gerontol A Biol Sci Med Sci 2000; 55:M10-16.

Takla MK, Razek NM, Kattabei O, El-Lythy MA. A comparison between different modes of real-time sonoelastography in visualizing myofascial trigger points in low back muscles. J Man Manip Ther 2016;24:253263.

Tous-Fajardo J, Moras G, Rodríguez-Jiménez S, Usach R, Doutres DM, Maffiuletti NA. Inter-rater reliability of muscle contractile property measurements using non-invasive tensiomyography. J Electromyogr
Kinesiol 2010;20:761-766.

Valencic V, Knez N. Measuring of skeletal muscles' dynamic properties. Artif Organs 1997;21:240-242.

Wilson HV, Jones A, Johnson MI, Francis P. The effect of inter-electrode distance on radial muscle displacement and contraction time of the biceps femoris, gastrocnemius medialis and biceps brachii, using tensiomyography in healthy participants. Physiol Meas 2019;40:075007.

Yu SH, Kim HJ. Electrophysiological characteristics according to activity level of myofascial trigger points. J Phys Ther Sci 2015;27:2841-2843. 